\title{
INSTITUSI PENGAWASAN PUBLIK (HISBAH) MENURUT IBNU TAIMIYAH
}

\author{
Elvira Sitna Hajar \\ Sekolah Tinggi Ilmu Ekonomi Ganesha - Indonesia
}

\begin{abstract}
Abstrak
Kitab "Al-Hisbah fi al Islam" adalah karya klasik karena ditulis 700 tahun silam oleh Syaikh Ibnu Taimiyah, namun relevansinya masih dirasakan sampai hari ini. Ada banyak pembahasan yang melampaui jamannya dan semakin terbukti urgensinya di masa modern. Hal tersebut menunjukkan bahwa ayat-ayat Al Qur'an dan Hadits Nabi Muhammmad saw yang menjadi rujukan utama bersifat abadi dan menjadi pedoman hidup manusia sepanjang jaman. Hisbah dapat didefinisikan sebagai lembaga pengawasan dan pengendalian terhadap harga komoditas di pasar (price control) serta pengawasan terhadap perilaku para pejabat pemerintahan. Yang istimewa dari karya beliau adalah tidak hanya merujuk kepada nash sebagai sumber normatif tapi juga mengikuti sejarah dan praktek masyarakat di sekelilingnya. Sehingga selain berkualitas secara ilmiah tapi juga dapat didiskusikan temuan-temuan baru di lapangan. Walaupun Ibnu Taimiyah dikenal sebagai ahli ilmu kalam dan fiqih, tapi kitab tersebut berbicara tentang tugas pemerintahan (public duties) dan ekonomi pasar (masalah yang menjadi perhatian utama masyarakat modern saat ini).
\end{abstract}

Kata Kunci: ibnu taimiyah, hisbah, pengawasan

\begin{abstract}
The book "Al-Hisbah fi al Islam" is a classic because it was written 700 years ago by Shaykh Ibn Taimiyah, but its relevance is still felt today. There are many discussions that are beyond their time and are increasingly evident in their urgency in modern times. This shows that the verses of the Qur'an and the Hadith of the Prophet Muhammad which are the main references are eternal and become the guidelines of human life throughout the ages. Hisbah can be defined as an institution for monitoring and controlling commodity prices in the market (price control) as well as monitoring the behavior of government officials. What is special about his work is that it does not only refer to texts as normative sources but also follows the history and practice of the people around him. So that apart from being scientifically qualified, new findings can also be discussed in the field. Although Ibn Taimiyah is known as an expert in kalam and figh, the book talks about public duties and market economy (issues that are the main concern of modern society today).
\end{abstract}

Keywords: ibn taimiyah, hisbah, supervision

Copyright (c) 2021 Elvira Sitna Hajar.

$\triangle$ Corresponding author : Elvira Sitna Hajar

Email Address : imranvira@gmail.com 


\section{PENDAHULUAN}

Hisbah berasal dari bahasa Arab, berakar kata ' $h a-s a-b a$ ' yang mempunyai arti cukup variatif, seperti "jumlah"; "pahala". Kata hasaba, yahsubu berarti "menghitung"; "menakar". Sedangkan bentuk verbal dari "ihtasaba" berarti "mempertimbangkan"; "mengharapkan pahala di akhirat dengan amal shalih pada hari perhitungan dengan Allah SWT".

Secara etimologis, hisbah berarti melakukan suatu tugas dengan penuh perhitungan berarti (bursar, treasurer). ${ }^{1}$

Definisi lain menyebutkan hisbah sebagai fungsi kontrol dari pemerintahan terhadap tindakan moral, agama dan ekonomi seseorang khususnya dan pada kehidupan publik pada umumnya, untuk mencapai keadilan berdasarkan prinsip Islam dan dikembangkan menjadi kebiasaan umum atau adat istiadat sesuai dengan waktu dan tempat. ${ }^{2}$ Singkatnya hisbah adalah lembaga yang mengontrol pasar dan adat moral.

Menurut Ibn Qayyim, hisbah dengan Ha berkasrah secara bahasa adalah "Menyuruh kepada kebajikan apabila telah nampak ditinggalkan dan mencegah kepada kemungkaran apabila telah nampak dilakukan. ${ }^{3}$ Dan menurut istilah hisbah adalah hukum sesama manusia yang tidak bergantung pada gugatan, yang asalannya menyuruh kepada kebaikan dan mencegah kejahatan yang telah ditetapkan Allah dan disampaikan oleh Rasūlulläh melalui kitabnya, sebagai petunjuk dan penerang bagi umatnya".4

Sedangkan yang bertanggungjawab atas adalah hisbah wali hisbah atau muhtasib. ${ }^{5}$

Tujuan hisbah seperti yang didefinisikan oleh Ibnu Taimiyah adalah perintah untuk melaksanakan kebaikan (al-ma'rüf) dan mencegah keburukan (al-munkar), yang juga merupakan tugas dari pemerintah dalam mengatur dan mengadili baik urusan umum ataupun khusus. yang tidak terjangkau institusi lain. ${ }^{6}$ Hisbah telah ada semenjak masa Rasūlullāh SAW. Beliau adalah muhtasib pertama dalam Islam. Beliau seringkali melakukan inspeksi untuk meninjau langsung aktivitas jual beli. Selanjutnya Nabi menunjuk Sa'id bin Ash bin Umayyah sebagai muhtasib di Makkah dan Umar bin Khatab sebagai muhtasib di Madinah. Pelembagaan hisbah dengan struktur yang lebih sempurna adalah pada masa Umar bin Khațāb. Hisbah pada masa Umar bin Khațāb mempuyai peran penting dalam pengawasan pasar dan kegiatan yang dilakukan di dalamnya, yaitu kegiatan ekonomi.

Tradisi ini dilanjutkan oleh dinasti Bani Umayyah, Bani Abbasiyah, Turki Utsmany hingga hisbah menjadi lembaga yang harus ada dalam setiap negara muslim. Hisbah menjadi departemen penting selama masa kekuasaan Bani Fatimiyyah, Ayyub dan Utsmaniyah. ${ }^{7}$

Di India, meski departemen hisbah yang resmi tidak ada, namun selama masa kesultanan, muhtasib dan qadli sama-sama ditunjuk setiap kali ada wilayah baru yang dikuasai oleh negara. Sedangkan Dinasti Moghul tidak nyaman dengan adanya lembaga hisbah karena rendahnya standar moral mereka sendiri, lalu mereka

1 Muhammad Djakfar, Hukum Bisnis Membangun Wacana Integrasi Perundangan Nasional Dewan Syariah, (Malang:UIN Press, 2009), h. 409

2 Control function of the goverment through persons acting especially in the field of morals, religon and economy, and generally in the areas of collective or public life, to achieve justice and righteousness according to the principles of Islam and commonly known good customs of time and place. Al-Mubarak, dalam Abdul Azim Islahi, Contributions of Muslim Scholars to Economic Thought and Analysis, (Jeddah: King Abdul Aziz, 2004), hal. 58

${ }^{3}$ Ibnu Qayyim al-Jauziyah, at-Thurūq al-Hukmiyah fi al-Siyāsah al-Syar'iyyah, (Jeddah :

Darul Ilmu Fawaid, t.th), hal. 620

4 Ibid.,hal. 622

5 Ibid., hal. 620

${ }^{6}$ Ibn Taimiyah, Al-hisbah fi al- Islām...hal. 18

${ }^{7}$ Ibnu Qayyim al-Jauziyah, al-Thurūq al-Hukmiyah...hal. 623-628 
menggantikannya dengan kotwal, yang memiliki jurusdiksi lebih terbatas daripada jurisdiksi muhtasib. Lembaga hisbah masih tetap popular sepanjang sejarah umat Islam, meski dinamakan berbeda-beda di berbagai tempat. Misalnya, di provinsi-provinsi Timur Baghdad, petugas pelaksananya disebut muhtasib, di Afrika Utara disebut shahib al-suq, di Turki disebut muhtasib aghasi dan di India disebut kotwal

Dengan berkembangnya kolonialisme Barat, hamper semua lembaga muslim mengalami modifikasi drastis. Seperti halnya dengan lembaga lain, hisbah juga mengalami kemerosotan efektifitasnya. Hisbah dipecah-pecah menjadi beberapa departemen atau menjadi anggotabadan negara yang tidakefektif. Sejak abad 19, Persia, Turki, Mesi dan India telah mengubah fungsi hisbah menjadi sejumlah departemen sekular dengan menganggap muatan religiusnya sebagai sesuatu yang tidak relevan.

Di Maroko, fungsi hisbah masih bertahan bahkan sampai awal abad ke 20. Pada jaman sekarang, dalam masyarakat Muslim, fungsi hisbah diserahkan kepada berbagai departemen pemerintah dan fungsi religiusnya dipindahkan ke posisi sekunder. Saudi Arabia adalah satu-satunya negara Muslim yang sampai saat ini masih mempertahankan sepenuhnya dimensi religius hisbah sampai suatu batas yang longgar, meskipun Saudi Arabia juga membagi-bagikan fungsi-fungsi sekular kepada sejumlah departemen dan kementrian. ${ }^{8}$ Di Romawi Timur yang telah melakukan kontak dengan dunia Islam melalui perang suci (Perang Salib), lembaga serupa juga di adopsi yang secara jelas dikenal dengan istilah mathessep yang berasal dari istilah muhtasib. ${ }^{9}$

Lembaga hisbah berfungsi sebagai pelaksana amar ma'rüf nahi munkar. Dengan demikian, terdapat rukun- rukun dalam hisbah, sebagaimana dijelaskan oleh Imam alGhazali: 10

“...bahwa rukun hisbah yang berkaitan dengan pelaksanaan yang ma'rüf dan mencegah yang munkar meliputi empat macam, yaitu, muhtasib (orang yang mencegah perbuatan munkar), muhtasab alaih (orang yang melakukan kemunkaran), muhtasib fiih (perbuatan yang dicegah) dan nafs al-Ihtisab (cara mencegah kemungkaran)..."

Berdasarkan definisi tersebut dijelaskan bahwa rukun hisbah ada empat, yaitu:11

a. Muhtasib yaitu orang yang menjalankan tugas-tugas hisbah dalam masyarakat dan negara Islam. Ia dilantik resmi oleh pemerintah untuk memastikan bahwa terlaksananya kebaikan dan ditinggalkannya kemungkaran.

b. Muhtasib 'Alaih yaitu orang yang melakukan al-munkar atau perilaku yang buruk. Dalam hal ini, Al-Ghazali menjelaskan tentang objek dari hisbah. Pertama, adanya perbuatan munkar, yaitu perbuatan yang dilarang agama, seperti minum khamar. Kedua, adanya perbuatan munkar yang mengakibatkan kecanduan sehingga melahirkan perbuatan munkar lainnya. Ketiga, perbuatan tersebut harus diketahui muhtasib. Keempat, perbuatan kemunkaran itu telah diakui dan disepakati oleh jumhur ulama, tanpa membutuhkan ijtihäd. Jika masih ada perdebatan, maka tidak dilakukan upaya nahi munkar. ${ }^{12}$

c. Muhtasib Fîh adalah segala bentuk kemunkaran yang dilarang melakukannya dan wajib dicegah, baik sudah mukallaf maupun yang tidak (segala usia). Kemungkaran yang akan menerima tindakan hisbah dibagi dalam dua bentuk: Bentuk positif, yaitu melakukan perbuatan-perbuatan yang dilarang oleh syara'

\footnotetext{
${ }^{8}$ Al-Mawardi, Al-Aḥkām As-Shultaniyah...hal. 240-259

${ }^{9}$ Nicola Ziadeh, hal.39

${ }^{10}$ Al-Ghazali, Ihyā Ulūmudîn.,hal. 308

11 Mohd. Parid Sheikh Ahmad \& Mohd. Azmi Omar, al-Hisbah dalam Ekonomi Islam, dalam Sheikh Ghazali Sheikh Abod Zamry Abdul Kadir (peny.), Pengurusan Perniagaan Islam, (Shah Alam : Hizbi, 1991), hal. 430

12 Mohd. Parid Sheikh Ahmad \& Mohd. Azmi Omar, al-Hisbah dalam ...hal. 434
} 
dan bentuk negatif, yaitu meninggalkan perbuatan-perbuatan yang dituntut oleh syara'.13 Pada umumnya, yang dimaksud dengan kemungkaran ialah setiap tindakan maksiat, yaitu tindakan-tindakan atau perbuatan-perbuatan yang menyalahi syariat Islam, baik daripada maksiat dosa besar atau dosa kecil, baik yang berhubungan dengan hak-hak Allah atau hak manusia. ${ }^{14}$ Anak kecil yang mau minum arak harus dicegah. Orang gila yang tidak tahu apa-apa, lalu ingin berbuat zina, maka wajib juga dicegah. Hal tersebut dimaksudkan oleh Al-Ghazali bertujuan untuk memenuhi kewajiban kepada Allah yang melarang perbuatan munkar dan menjaga manusia yang terdhalimi. 15

d. Nafs al-Ihtisab adalah cara mencegah kemunkaran. Tujuan daripada tindakan hisbah adalah menghapuskan kemungkaran serta menggantikannya dengan kebaikan dan kemaslahatan. Untuk mencapai tujuan hisbah tersebut, tindakantindakan hisbah hendaklah berlandaskan fiqih yang mendalam serta beberapa kaidah berikut ini :16 (1). Ketetapan hati dalam menolak segala tindakan kemungkaran, agar jiwa selalu siap dalam menindak pelaku kemungkaran. (2). Tindakah hisbah mestilah dilakukan untuk merubah kemungkaran dan kerusakan untuk memperoleh kemaslahatan. (3). Tindakan hisbah dilakukan selembutlembutnya, sehingga ia mendorong kepada penerimaan, kerelaan dan kegembiraan pihak-pihak yang dihisbah. Disebutkan oleh Al-Ghazali bahwa dalam melaksanakan hisbah harus mengedepankan etika dan moral, karena dari sekian banyak kriteria untuk seorang muhtasib (integritas, wawasan, pandangan dan status sosial yang tinggi), ilmu pengetahuan, kelembutan dan kesabaran dianggap sebagai kualitas-kualitas yang terpenting.

Muhtasib secara teknis dapat menunjuk staf ahli yang membantunya dalam mengawasi hubungan antar bermacam profesi dan perdagangan. Dalam hal ini muhtasib memiliki kewenangan yang besar. Ia dapat menerima pengaduan dari publik atau dapat juga mengambil inisiatif sendiri, akan tetapi harus berhati-hati dalam menggunakannya.

Langkah-langkah yang dapat diambil oleh seorang muhtasib dapat berupa: saran, teguran, kecaman, penjara bahkan pengusiran dari kota. Dan sangsi terberat ditetapkan oleh muhtasib hanya apabila sangsi yang ringan tidak efektif dan berpengaruh kepada terhukum.

Dengan demikian peraturan dari muhtasib menjadi system pengawasan dan pengendalian (check and balances). Contohnya, muhtasib tidak boleh terlibat dalam penyelidikan rahasia atas urusan-urusan yang meragukan, menindak tegas jika perilaku orang sudah bertentangan dengan ketentuan syariah. Hal ini berlaku pula kepada muhtasib jika ingin berijtihad untuk menjatuhkan hukuman kepada seseorang maka muhtasib tidak diperbolehkan melakukan hal tersebut, dia hanya diperbolehkan untuk melarangnya melakukan perbuatan yang memang sudah ada ijma'umat tentang hal tersebut. Semua perbuatan dan tindakan muhtasib tidak boleh menibulkan masalah yang lebih besar daripada masalah yang hendak ia hilangkan.

Ini artinya bahwa sebelum muhtasib hendak menghapuskan suatu praktik kejahatan dari kelompok yang kuat, ia terlebih dahulu mempunyai rencana yang matang dan efektif untuk mengantisipasi reaksi balik dari mereka. Dan mengenai

13 Ibid

14 Al-Ghazali, Ihyā Ulūmudîn ...hal. 332-333

15 Mohd. Parid Sheikh Ahmad \& Mohd. Azmi Omar, al-Hisbah dalam ...hal. 442

16 Syaikhul Islam Ibnu Taimiyyah' Al Hisbahwa Yahtawi ala al-Amru bi al Ma'ruf wa an-Nahyu an al-Munkar wa al-Masail al-Mutafariqah min al-Majmu' (Hisbah, Institusi Pengawasan Publik), pernerjemah: tim hisbah centre, (Jakarta :Hisbah Centre for Reform, 2016), hal. 154 
masalah adat masyarakat, muhtasib harus melibatkan masyarakat untuk berpartisipasi dalam mengatasinya bukan mengedepankan pendapat sendiri.

Lembaga hisbah adalah kontribusi umat muslim untuk peradaban umat manusia. Oleh sebagian orientalis dinyatakan bahwa lembaga ini meminjam konsep dari lembaga hisbah dari Romawi, yaitu agronomos di pasar-pasar mereka yang biasa menjalankan tugas yang sama dengan lembaga hisbah. Perbedaan mendasarnya adalah lembaga hisbah Muslim berkembang dari ajaran Al Qur'an tentang amar ma'ruf nahi munkar dan memiliki cakupan yang luas daripada agronomos bangsa Romawi. Jabatan muhtasib hanyalah kebutuhan logis dari negara Islam untuk menegakkan dan menjalankan norma-norma sosialnya. Hisbah bukan semata-mata lembaga sekuler untuk mengatur pasar dan mengelola layanan publik.

Literature tentang lembaga hisbah dapat diklasifikasikan dalam dua kategori. Sebagian membahas tentang prinsip-prinsip hisbah dan amar ma'ruf nahi munkar. Sebagian kategori yang lain merincikan hak dan kewajiban muhtasib.

Penilaian kritis atas dasar hak dan kewajiban muhtasib menunjukkan bahwa hamper di semua perdagangan dan jasa yang terdaftar, telah mengalami metamorphosis sempurna bersamaan dengan perkembangan industrialisasi, produksi dengan skala pasif, perluasan pasar dan perkembangan kredit dan pembiayaan modern. Namun jika kita dominan menganalisis lebih dalam tugas-tugas tersebut, maka ada tiga standar utama yang tampak:(17)

Pertama, muhtasib memilki tanggung jawab untuk memastikan masyarakat secara keseluruhan memiliki organisasi dan fasilitas yang memadai untuk menjalankan ibadah. Sarana prasarana masjid, penunjukan muadzin dan imam, menjadwalkan shalat lima waktu, shalat juma'at dan shalat Ied, adalah sebagian dari tugasnya. Demikian pula ia akan melarang ketidak taatan kepada kewajiban syariahlain yang dilakukan individu maupun kolektif. Tugas muhtasib ini dapat diadopsi bahkan sampai saat ini jika lembaga ini memang bisa dibentuk.

Kedua, muhtasib memantau penegakan keadilan di masyarakat. Ia berusaha untuk menegakkan fair play dalam berbagai sektor ekonomi guna meminimalisir eksploitasi yang mungkin terjadi di dunia ekonomi. Demikian pula muhtasib harus memantau adanya manipulasi harga, pasokan dan produksi, kolusi monopolitis, penipuan, kecurangan dan setiap bentuk ketidakadilan antar sector. Secara garis besar, ia harus mengintervensi setiap kali jalannya roda ekonomi dipermainkan oleh perorangan atau kelompok yang secara ekonomi kuat demi kepentingan pribadi mereka. Wilayah tugas muhtasib yang ini perlu disesuaikan dengan pola-pola produksi, distribusi dan pertukaran zaman sekarang. Semangat keadialan harus tetap dijaga selagi menentukan peran berbagai agen ekonomi.

Ketiga, muhtasib memberikan perhatian khusus terhadap berbagai layanan umum khususnya kondisi kesehatan kota. Ia harus memantau seluruh pengelolaan kota, contohnya penerangan jalan, pengelolaan sampah, desain arsitektur bangunanbanguna kota, pasokan air dan sanksi-sanksi antipolusi.

\section{METODE PENELITIAN}

Tulisan ini menggunakan kajian literature yang sepanjang dapat ditemui dan dimiliki dengan memperhatikan dan mengamati terkait dengan kompetensi yang terdapat dalam ajaran Islam. Asumsi-asumsi yang ditemui dalam kajian tersebut dieksploratif untuk dipahami dan dianalisis dengan membandingkan antara literature satu dengan yang lainnya dengan tujuan untuk mendapatkan gambaran awal yang dapat dijadikan kajian lanjutan secara mendalam dan komprehensif. Secara sederhana metode yang digunakan dalam tulisan ini adalah deskriptif kualitatif. 


\section{HASIL DAN PEMBAHASAN}

Gambaran yang dominan dalam ekonomi Islam seperti yang terlihat dalam literature hisbah, dapat disebutkan sebagaimana berikut ini:(18)

\section{Mengelola Keseimbangan}

Sebagian tugas muhtasib menunjukkan bahwa ekonomi secara aktif dikelola oleh negara. Ekonomi sendiri memelukan tindakan-tindakan korektif oleh negara jika diperlukan. Keseimbangan ekonomi direkayasa untuk mencapai tingkat efisiensi dan keadilan yang masuk akal.

\section{Mengatur Pasokan}

Muhtasib mengatur produksi dab pasokan barang dan jasa dengan berbagai cara:

Pertama, ia harus memastikan bahwa semua sumber daya tidak mengalir kepada produksi dan distribusi barang dan jasa yang secara kategoris adalah haram menurut syariah. Kedua, muhtasib harus selalu ketat mengawasi posisi pasokan barang-barang kebutuhan pokok, khususnya bahan makanan. Pada saat krisis, muhtasib dapat memaksa para penimbun untu mengeluarkan simpanan mereka ke pasar. Ketiga, semua perdagangan harus dilakukan di pasar yang terbuka. Kontrak-kontrak rahasia antar pedagang di runah dan gudang mereka, dapat mengganggu stabilitas tingkat harga yang alami. Keempat, para pedagang tidak boleh bersepakat untuk menawarkan harga yang tinggi dalam artifisial. Di sini terlihat jelas pentingnya tindakan anti monopoli oleh negara. Kelima, para pedagang tidak boleh membentuk kelompok untuk mencegah masuknya pemain baru di pasar. Akses bebas ke dalam pasar dijamin untuk siapa saja yang ingin masuk ke pasar. Keenam, para pedagang kota tidak diijinkan menjemput pemasok desa di tengah jalan dan membeli produk mereka dengan harga yang lebih murah. Hal ini dilakukan agar mencegah pemasok desa mengetahui tingkat harga pasar yang layak. Inilah yang mengakibatkan persaingan tidak sehat antar pedagang. Dan tugas muhtasiblah yang harus menyebarkan informasi terkait harga pasar kepada pemasok desa yang tidak mengetahui informs tersebut. Hal demikian ini dapat mencegah terjadinya kecendrungan untuk membeli dengan harga yang lebih murah dari petani. Ketujuh, perantara (makelar), yang tidak menambahkan sedikitpun manfaat pada produk dan hanya memanfaatkan margin dari penjual dan pembeli, harus disingkirkan. Hal ini dilakukan untuk melancarkan arus pasokan dan meniadakan sekelompok exploiter. Kedelapan, melindungi kepentingan para pedagang dari tindakan dumping di pasar oleh sekelompok kecil orang.artinya bahwa jika perorangan atau sekelompok kecil pengusaha meluncurkan pola produksi baru yang lebih murah, maka akan mengakibatkan keusangan teknologi dengan skala massal, pengangguran dan penutupan pabrikpabrik. Untuk mencegah situasi seperti itu, peluncuran teknologi baru harus dilakukan secar bertahap sehingga mereka yang terkena dampaknya dapat menyesuaikan diri dengan baik dan negara juga harus menyediakan pembiayaan jangka pendek bagi mereka yang terkena dampak tersebut. Tindakan ini dapat membantu memberikan dorongan dan aliran produksi. Kesembilan, para pedagang dan produsen tidak diizinkan menyembunyikan cacat dari produk mereka. Dan mereka juga tidak diperbolehkan membuat sumpah palsu demi menjual produk-produk mereka. Hal ini menunjukkan bahwa muhtasib mengatur peran periklanan dalam konteks jaman sekarang. Label-label produk dan iklan melalui media bisa difilter sebelum dipublikasikan untuk menjamin akurasi imformasi mereka.

\section{Kontrol Harga}

Control harga atau tas'ir, dalam keadaanyang normaltidakdiijinkan menurut syariah. Nabi saw pernah diminta utnuk menetapkan harga di pasar 
Madinah ketika harga-harga mengalamikenaikan yang tinggi dan nabi menolaknya dengan alasan bahwa harga harus berkembang secara alami. Dan oleh sebagian fuqoha mengambil kesimpulan dari kasus ini bahwa tas'ir tidak diperbolehkan dalam keadaan bagaimanapun.

Namun lain halnya dengan Imam Ibnu Taimiyyah yang telah membahasnya panjang lebar dan disimpulkan bahwa tas'ir tidak boleh dilaksanakan apabila tidak ada hambatan artifisial (tidak alami) dalam menentukan tingkat harga di pasar. Namun jika hambatan-hambatan tersebut ada di pasar sehingga tingkat harga dikendalikan oleh sekelompok orang yang secra ekonomi kuat demi keuntungan mereka, maka muhtasib memiliki kewajiban untuk menetapkan ukuran-ukuran yang benar. Karena salah satu tujuan syariah adalah menegakkan keadilan dan untuk menjaga kepentingan umum dari kesulitan. Para pedagang yang curang juga akan dijatuhi hukuman. Artinya bahwa dalam konteks sekarang muhtasib harus harus selalu menguasai informasi tentang kondisi ekonomi secara keseluruhan dan juga struktur harga dalam ekonomi.

\section{Struktur Kredit}

Panduan-panduan muhtasib menggambarkan muhtasib bertugas memantau transaksi yang mengandung riba. Hal ini dapat terjadi dalam jual beli, barter barang, barter logam mulia atau transaksi hutang piutang. Unsur-unsur riba bisa masuk ke dalam kontrak-kontrak tersebut. Nuhtsib biasanya menetapkan bentuk-bentuk kontrak yang diperbolehkan syariah dan bentukbentuk yang mengandung riba. Hai ini membuktikan kuat bahwa riba tidak dilarang dalam ekonomi Islam.

Literature hisbah dapat menjadi sumber inspirasi bagi penelitian tentang kredit bebas riba di dunia Islam. Dalam kasus debitur yang tidak mampu melunasi hutangnya sampai jatuh tempo, muhtasib mengatur bantuan untuknya dari dana zakat. Hal ini menunjukkan bahwa lembaga qardl hasan ditopang dengan jaminan negara dan dapat memberikan petunjuk untuk merencanakan sistem tersebut agar bisa digunakan dalam ekonomi modern seperti sekarang ini.

5. Hak Milik

Hak milik pribadi dihormati dan dilindungi dalam ekonomi Islam. Akan tetapi hak tersebut tidak mutlak. Negara memiliki hak untuk mengatur penggunaan hak milik untuk kepentingan umum. Artinya bahw sumber daya umum tidak dapat dibiarkan menjadi hak istimewa kelompok tertentu di masyarakat.

\section{Pemanfaatan Sumber Daya Manusia}

Salah satu dari tugas muhtasib adalah mengawasi pengemis secara ketat dan kaum lemah ekomomi diberi kebutuhan dasar hidup dari zakat dan sedekah umat. Muhtasib dalam hal ini dapat memaksa orang-orang kaya dan mampu, untuk berpartisipasi dalam memenuhi kebutuhan tersebut.

Muhtasib bertanggung jawab khusus atas budak-budak atau kaum buruh (konteks sekarang) dalam mendapatkan gaji yang layak untuk mencukupi kebutuhan dasar hidupnya. Muhtasib juga bisa menintervensi negosiasi antar serikat buruh dengan serikat pengusaha.

\section{Efesiensi di Sektor Publik}

Sejatinya, secara tradisional, muhtasib harus mendorong penguasa untuk mengadopsi perilaku yang ma'ruf dan menghentikan perilaku yang munkar. Seperti yang disabdakan Nabi saw bahwa sebaik-baik jihad adalah mengatakan kebenaran di hadapan penguasa yang kejam. 


\section{KESIMPULAN}

Dalam sejarah Islam, hisbah merupakan sebuah lembaga yang mempunyai tugas memantau dan mengawasi praktik-praktik kegiatan perekonomian agar sesuai dengan Al-Qur'ān dan Hadist. Proses sejarah hịsbah yang panjang dari masa Rasūlullāh hingga seterusnya, dapat disimpulkan betapa pentingnya pengawasan dalam setiap kegiatan yang dilakukan manusia termasuk kegiatan ekonomi.Tanggung jawab muhtasib dan fungsi hisbah menunjukkan bahwa di dalam sistem ekonomi Islam, hal-hal yang berkaitan dengan ekonomi dipegang oleh negara dan tidak dibiarkan begitu saja mengikuti arus.

Konsekuensi dinamika kehidupan masyarakat yang semakin kompleks dan canggih, memunculkan berbagai lembaga yang mengawasi etika dan keadilan ekonomi. Sehingga kehadiran lembaga pengawas menjadi sangat signifikan dan dibutuhkan. Untuk menjaga kemurnian penerapan nilai-nilai syari'ah pada praktek perbankan syari'ah dibutuhkan lembaga pengawas syariah yang berkualitas, berkapasitas, berkompeten dan kredible, yaitu memiliki kemampuan yang memadai di bidang syariah, hukum, serta pengetahuan tentang keuangan dan perbankan, sebagai contohnya.

\section{DAFTAR PUSTAKA}

Abdul Azim. 2004. Contributions of Muslim Scholars to Economic Thought and Analysis, Jeddah: King Abdul Aziz

Ahmad, Mohd. Parid Sheikh \& Mohd. Azmi Omar. 1991. al-Hisbah dalam Ekonomi Islam, dalam Sheikh Ghazali Sheikh Abod Zamry Abdul Kadir (peny.), Pengurusan Perniagaan Islam, Shah Alam : Hizbi, Musta'in. 1986. al-Sūq wa Tanzimatuh fi alIqtișād al-Islami, Khortum : Darul Sudaniyah lil Kutub

Al-Mawardi,. 2006. Al-Aḥkām As-Sultaniyyah fi Al-Wilāyah Ad-Diniyyah, alih bahasa Fadli Bahri, Cet. 2 Jakarta: Darul Falah Jauziyati, Ibnu Qayyim. 2001. Radul Mi'ad Fi Hadyin Khoirin, Beirut : Muasasat al- Risalah

Al-Jauziyah, Ibnu Qayyim. at-Thurūq al-Hukmiyah fi al-Siyāsah al-Syar'iyyah, Jeddah : Darul Ilmu Fawaid

Al-Ghazali, Ihyā Ulūmudîn

Ibnu Taimiyah, Al-Hisbah fil Islam, Kairo: Daar al-Sha'ab, 1976

-------, Tugas negara Menurut Islam, Yogyakarta : Pustaka Pelajar, 2004

-, Al Hisbahwa Yahtawi ala al-Amru bi al Ma'ruf wa an-Nahyu an al-Munkar wa al-Masail al-Mutafariqah min al-Majmu' (Hisbah, Institusi Pengawasan Publik), pernerjemah: tim hisbah centre, (Jakarta :Hisbah Centre for Reform, 2016

Djakfar, Muhammad, Hukum Bisnis Membangun Wacana Integrasi Perundangan Nasional Dewan Syariah, Malang:UIN Press, 2009

Ziadeh, Nicola.(1963).al-Hisbah wa al-Muhtasib fi al-Islam.Beirut: Catholic Press. 